\title{
Effect of Season on Reproductive Performance of Bhagnari Cattle Managed Under Semi Intensive Management Condition
}

\author{
Hamzo Khan Kunbhar ${ }^{*}$, Syed M Sharif ${ }^{2}$, Huma Rizwana ${ }^{3}$, Zahid Iqbal Rajput ${ }^{4}$, Raiz Ahmed Leghari ${ }^{5}$ and \\ Mughal GA ${ }^{3}$ \\ ${ }^{1}$ Department of Animal Reproduction, Faculty of Animal Husbandry and Veterinary Sciences, Sindh Agriculture University Tandojam, \\ Pakistan \\ ${ }^{2}$ Department Animal Husbandry, Baluchistan, Pakistan \\ ${ }^{3}$ Department of Livestock Management, Faculty of Animal Husbandry and Veterinary Sciences, Sindh Agriculture University \\ Tandojam, Pakistan \\ ${ }^{4}$ Department of Veterinary Microbiology, Shaheed Benazir Bhutto University of Animal and Veterinary Sciences, Sakrand, Pakistan. \\ ${ }^{5}$ Department of Veterinary Medicine, Faculty of Animal Husbandry and Veterinary Sciences, Sindh Agriculture University Tandojam, \\ Pakistan
}

Received: 17 July, 2017; Accepted: 4 September, 2017; Published: 12 September, 2017

*Corresponding author: Hamzo Khan Kunbhar, Assistant Professor, Department of Animal Reproduction, E-mail: drkunbhar@gmail.com

\begin{abstract}
This study was conducted to investigate the effect of season on some of productive and reproductive performance of Bhagnari cattle maintained under semi intensive management condition at Usta Mohammad Cattle Farm, Baluchistan. The record of one hundred cows of Bhagnari breed were selected and utilized in this study, out of those the records of 84 cows were used for age at puberty, the calving record of 294 cows for calving intervals and 294 cows milk records for milk yield were evaluated to determine the effect of season on age at puberty, calving interval and milk yield. The season of the year was divided in to four seasons i.e. spring, summer, autumn and winter. The result revealed that the overall mean age at puberty, calving interval and milk yield was recorded as $935.56 \pm 55.221$ days, $415.935 \pm$ 8.179 days and $785.723 \pm 12.228$ liters respectively during present study. The season of the year was significant $(\mathrm{P}<0.005)$ effect on age at puberty, calving interval and milk yield. The calves born in winter season reached to puberty at early age (816.14 \pm 51.307 days) than the calves born in other seasons. The cow calved in winter season had shorter calving interval (391.25 \pm 7.122$)$ and produced more milk $(875.72 \pm 8.45)$ as compare to other seasons. It was found that the season of the year has significant effect on the performance of a cow. The winter season was found more favorable in terms of reproductive performance and milk yield in Bhagnari cattle.
\end{abstract}

Keywords: Bhagnari; Cattle-Breed; Season; IntensiveManagement; Reproduction-Performance

\section{Introduction}

Pakistan bestowed with a large number of livestock population and 3rd largest milk producer country in the world after China and India. In Pakistan, the livestock raising is one of the biggest industry. The animals and the products obtained from them contributed billions of rupees in to the national economy in each year. In agriculture; the livestock contributed about $55.9 \%$ while 11.8 percent was contributed in to the national GDP during the year 2013-14 (GOP, 2013-14) [1]. In past, the cattle were kept for draught and meat purpose only. Later on, with the industrialization, the cattle occupied the place of dairy and meat animal [2]. Limited feed resources demands better utilization of animal wealth in the country. In Pakistan, there are more than ten distinct cattle breeds among those, Red Sindhi, Sahiwal, Thari, Dhajal and Bhagnari are most popular cattle breeds [3].

The Bhagnari cattle is a draught breed and found in Bhag territory in north of district Jacobabad Sindh and district Sibi, Baluchistan. The Bhagnari cattle has the ability to survive in hard and harsh environmental conditions and has resistance power against various diseases as compared to other cattle breeds [4]. The production and reproduction of the animals are directly under the influence of genetic potential of the animal, environment, nutrition, management of farm and the staff involved. Under optimal condition a cow heifer should attend puberty at an early age, conceive to fertile mating, produce a viable calf, return to estrus early after calving and again become pregnant and repeat this cycle at regular interval till the end of its productive life. The opened days in between $60-90$ could be considered as standard reproductive index. This process insures a harvest of more milk and calf crops during life time of animal. Delay at any stage causes great economic losses to farmers and dairy producers [5].

The success in production is related to several factors of reproductive performance which includes such as age of puberty, age at first calving, post-partum estrus, calving intervals, effect of season and ultimately the milk yield. The poor reproductive performance of the animals resulting decline in herd fertility, 
prolonged calving intervals, reduction in milk production and increases culling rate and finally economic losses of the farm. The season of calving infect has significant effect on the overall performance of the animal [6]. However some work has been carried out to assess the effect of season on reproductive performance of Red Sindhi and Sahiwal cattle breeds, but Bhagnari breed had received very little attention, hence it is the need of time to determine the effect of season on reproductive performance of Bhagnari breed. This study was therefore designed to investigate the effect of the season on the age at puberty, calving intervals and milk production of Bhagnari cattle breed, maintained under semi intensive management conditions of tropical climate in Baluchistan.

\section{Materials and Method}

The study was conducted to investigate the effect of season on some productive and reproductive performance of Bhagnari cattle maintained under semi intensive management condition at Usta Mohammad Cattle Farm, district Nasirabad, Baluchistan. The data were collected on reproductive and productive performance of Bhagnari cows from the record available at the farm to evaluate the effect of season on reproductive performances. The total records of one hundred cows of Bhagnari breed were utilized for this study, out of those the records of 84 cows were selected for age at puberty, the records of 294 cows for calving interval and milk yield were evaluated to determine the effect of season of the year on age at puberty, calving intervals and milk yield. The season of the year was divided in to four seasons spring summer, autumn and winter. The animals were placed in tail to tail management system. The cows were milked twice in a day (morning and evening); Hand milking was practiced at the farm. Vaccination and deworming were adopted at the farm as per scheduled. The seasonal green fodders, wheat straw and the concentrate ration (wheat bran, rice bran and cotton seed cake) were fed in portions twice a day and common salt blocks were placed in the mangers for licking. The animals were free access to fresh water round the clock. The data were recorded in a separate proforma specially designed for this purpose. The data were Analyzed Statistically Using Standard Statistical Analysis Of Variance (ANOVA) and simple T-test was applied to ascertain the significant difference among the seasons.

\section{Results and Discussion}

\section{Effect of Season on Age of Puberty}

The study was conducted to investigate the effect of season on reproductive performance of Bhagnari cattle. The results found in the present study for various parameters were discussed in light of the comparison to the results of other researchers reported in the literature. The average age at puberty of Bhagnari cattle was recorded as $816.14 \pm 51.307$ days in calves they born in winter, $877.43 \pm 46.858$ days in spring, $956.54 \pm 53.608$ days in autumn and $1092.76 \pm 69.109$ days in summer born calves (Table 1). The delayed age at puberty was recorded in calves they born in summer as compared to winter, spring and autumn seasons. The analysis of data showed a significant $(p<0.05)$ effect of season on

\begin{tabular}{|c|c|c|}
\hline Season & $\begin{array}{c}\text { No. of } \\
\text { observation }\end{array}$ & Mean $( \pm$ SEM)puberty age (days) \\
\hline Winter & 21 & $816.14 \pm 51.307 \mathrm{a}$ \\
\hline Spring & 21 & $877.43 \pm 46.858 \mathrm{~b}$ \\
\hline Summer & 21 & $1092.76 \pm 69.109 c$ \\
\hline \multirow[t]{2}{*}{ Autumn } & 21 & $956.54 \pm 53.608 \mathrm{~d}$ \\
\hline & & $935.555 \pm 55.221$ days $(31.185$ moths $)$ \\
\hline
\end{tabular}

age of puberty in Bhagnari cows. The results recorded in current study were in agreements to the results of Sattar, et al. [7]. They reported that the age of puberty in calves they born in winter attained an early age of puberty than the calves born in spring followed by autumn and summer. Similar trend was also reported by Javeed, et al. in Jersey cows [8]. They reported that the higher age at puberty was in calves they born in summer season and the shorter in winter season. The calving season had significant influence on the age at puberty $[9,10,11]$. The age of cows was more than 27 months and calved at the age of 39 months had the longer first service period (92.6 \pm 4.5 days) after parturition in comparison to those cows they reached of an puberty age of 20 months and calved less than 29 months of age had shorter service period after parturition $[9,11]$. They reported results were in accordance with the findings of the current study, whereas similar trend was reported that the season has a significant effect on the age of puberty $[9,11]$.

The finding of the current study were in agreement with those, who observed that the winter born heifers conceived at an earlier age than summer and autumn born heifers [10]. The delayed in onset of puberty in calves born in summer season may be due to the high environmental temperature, hence the calf remained under heat stress and perhaps received less milk in take. The discrepancy of season may be attributed due to the availability of green fodders in the area and environmental condition in attaining early puberty age.

\section{Effect of Season on Calving Interval}

The calving interval extensively/probably is the best index of cattle herds of reproductive efficiency. Long days opened and prolonged calving interval may affect the overall the revenues of the dairy herd. In present study the mean calving interval was recorded as $415.935 \pm 9.896$ days, whereas it was reported in various seasons of the year as $452.32 \pm 8.711$ days in summer, $435.32 \pm 9.68$ days in autumn, $414.85 \pm 7.202$ days in spring and whereas in winter it was $391.25 \pm 7.122$ days. The maximum calving interval (452.32 days) was found in cows calved in summer season as compared to winter followed by spring and autumn seasons. The season of calving had significant $(p<0.05)$ effect on the calving interval (Table 2).

The findings of current study were in line with the result of Iiatsia, et al. and Bajwa, et al. [12, 11]. They reported that the 


\begin{tabular}{|l|c|c|}
\hline \multicolumn{2}{|c|}{ Table-2: Effect of season on calving interval in Bhagnari cows } \\
\hline Season & $\begin{array}{c}\text { No. of } \\
\text { observations }\end{array}$ & $\begin{array}{c}\text { Mean ( } \pm \text { SEM) calving interval } \\
\text { (days) }\end{array}$ \\
\hline Winter & 106 & $391.25 \pm 7.122 \mathrm{a}$ \\
\hline Spring & 29 & $414.85 \pm 7.202 \mathrm{~b}$ \\
\hline Summer & 123 & $452.32 \pm 8.711 \mathrm{c}$ \\
\hline Autumn & 36 & $435.32 \pm 9.68 \mathrm{~d}$ \\
\hline & & $415.935 \pm 8.179$ days $(13.865$ days) \\
\hline$P<0.034$ & & \\
\hline
\end{tabular}

cows calved in summer were longer calving intervals (456.88 days) than winter calved cows (412.90 days). The similar trend was reported by Maryam et al. that the cows calved during warm months was longer calving interval as compared to cold months [13]. However the results of the present study were also in accordance with the results reported by Pawar, et al. and Mammoud, et al. $[9,10]$. They reported that the calving season has significant effect on reproductive performance of the cow. In contrast to the results of current study that the cows calved in spring had longer calving interval ( $409.4 \pm 5.2$ days) as compared to those calved in summer, autumn and winter seasons. The cows calved in the dry season had an average shorter calving interval (417 days) as compared to ( 435 days) those calved in wet season [14]. Furthermore they reported that cows calving in autumn usually reconceived in the following season (January), while those calving in January were unlikely to conceive during the subsequent mating period.

The extended calving interval negatively affects the productive life of the cow; because of the cow has few lactation numbers during the life period as compared to those cows with shorter calving intervals [15]. The difference was because of the fact that the cows calved in the dry season had high significant effect of season of calving and would take an advantage of improved nutrition during the subsequent rainy season to meet their maintenance and nutritional requirement. The significant effect of season of calving on the reproductive performance of dairy cows could be attributed due to the changes in feeding, management and environmental conditions. Long calving interval was observed in present study could be due to the heat stress because of increased in temperature, that maybe reduce feed intake, that may depressed in ovarian activity and poor estrus occurrence in Bhagnari cattle, maintained in harsh and hard climate conditions. The days open are the part of the calving intervals that can be reduced by improvising the herd management practices and out crossing.

\section{Effect of Season on Milk Yield}

In the present study an average milk yield was recorded as $785.723 \pm 12.228$ liters, whereas it was higher in winter $(875.72$ \pm 8.444 lit) calved cows followed by spring (820.2 \pm 11.39 lit), autumn (731.32 \pm 15.489 lit) and summer (715.65 \pm 13.588 lit) season. A significant $(P<0.05)$ effect of season on milk yield was found during present study in Bhagnari cows (Table 3). The
Table-3: Effect of season on milk yield in Bhagnari cows

\begin{tabular}{|c|c|c|}
\hline Season & No. of observation & \begin{tabular}{c} 
Mean ( $\begin{array}{c}\text { S.E) milk yield } \\
\text { (liters) }\end{array}$ \\
\hline Winter
\end{tabular} \\
\hline Spring & 106 & $875.72 \pm 8.444 \mathrm{a}$ \\
\hline Summer & 123 & $820.2 \pm 11.391 \mathrm{a}$ \\
\hline Autumn & 36 & $715.65 \pm 13.588 \mathrm{~b}$ \\
\hline$P<0.041$ & & $731.32 \pm 15.489 \mathrm{~b}$ \\
\hline
\end{tabular}

results of currents study were in line with the results reported in Red Sindhi cattle $[16,7]$. They reported that the more milk yield was recorded in winter calving cows. However; similar trends was reported for higher milk yield (3801 lit) in winter season as compared to summer (3486 liters) season [8]. The milk production was usually less during summer season because of heat stress and shortage of green forages [14].The findings of the current study were in close agreements to the results reported by Bajwa, et al. [11]. They reported that the milk yield was significantly affected $(P<0.05)$ by season of calving. The higher milk yield was reported in cows calved in winter season; followed by rainy and summer seasons [9]. The results reported by Ahmad, et al. and Baloch were also in agreements with the findings of current study for milk yield $[6,17]$. They also reported that the season of calving had a significant effect $(P<0.05)$ on milk yield.

The cows calving in winter and spring seasons showed the higher milk production than those calved in the summer season [18]. The similar trend of observation was reported by Hassan and Khan, [15]. They reported higher milk production (25528 lit) in autumn and lowest in summer. Whereas the findings of Javeed, et al. and Raza, et al. were not different from the observation recorded in current study $[8,19]$. In contrast to the finding of current study the daily milk production was significantly higher $(P$ $<0.01$ ) in cows that calved in summer and autumn than those that calved in winter and spring [20]. Increase in production caused by maturation and increase in body weight $[21,6]$. The cows of the same age but different parity were variation in production $[22,6]$. The increase in milk production in autumn was due to decreased of summer heat stress. In summer, high ambient temperature adversely affects the overall animals' production [8]. The effect of variation in season on reproductive activities could be due to the difference in photoperiod among the seasons or to be seasonal differences innutrition. The increase in global temperature also negatively affects the reproductive performance of a cow. The reproductions of dairy cows are extremely sensitive parameter to heat stress [18]. Consequently, the combined effect of season, heat stress and milk production for decreasing the conception rate of dairy cows was reported higher in summer season.

\section{Conclusion}

AIt was observed that the Bhagnari cattle are low milk producer, attained late age of puberty and having a long calving interval and less milk production. The winter season was 
found more suitable in terms of milk yield and reproductive performance of Bhagnari breed. On the basis of the results of the study, it is suggested that the cross breeding program may be introduced to reduce the age at puberty, calving intervals and increase milk production of this indigenous cattle breed. The estrus synchronization program may be launched to rotate the cycle of animals that may parturite during winter season to take an advantage of the season of the year for getting higher milk yield.

\section{References}

1. GOP. Pakistan Economic Survey 2013-14. Government of Pakistan Economic Adviser's Wing, Finance Division, Islamabad 2014.

2. Afzal M, AN Naqvi. Livestock resources of Pakistan: Present status and future trends. Quarterly Science Vision. 2004;9(1-2/3-4):1-14.

3. Khan M S, M A Khan, S Mahmood. Genetic resources and diversity in Pakistani goats. International journal of agriculture and biology 2008;10(2):227-231.

4. Kunbhar H K, S M Sharif, A A Memon, S H Abro, R Abro, V Suthar,et al Reproductive performance of Bhagnari cattle breed managed under semi intensive management condition. Pure and Applied Biology 2016;5(3):615-621

5. Kunbhar H K, A B Lasi , A A Memon. Reproductive performance of Crossbreed cattle maintained at Nagori cattle farm. Nagori society. Karachi. Sindh. Pakistan. Journal of Advances in Animal and Veterinary Sciences. 2015;3(5):7-12.

6. Ahmed M K A, A B Teirab, L M A Musa and K J Peters. Milk production and reproductive traits of different grades of zebu $\mathrm{x}$ Friesian crossbreds under semi-arid conditions. ArchivaAnimal Breeding. 2007;50(3):240-249.

7. Sattar A, I Ahmed, R H Mirza. Reproductive efficiency of Jersey under subtropical condition of the Punjab. Pakistan Veterinary Journal. 2004;24(3):129-133.

8. Javed K, M Afzal, A Sattar, R H Mirza. Environmental factors affecting milk yield in Friesian cows in Punjab. Pakistan. Pakistan Veterinary Journal. 2004;24(2): 58-62.

9. Pawar H N, G V P P S R Kumar, R Narang. Effect of year, season and parity on milk production trait in Murrah buffaloes. Journal of Buffalo Science. 2012;1(1):122-125.

10. Mammoud M H, S Z El-Zarkouny, E Z M Oudah. effect of sire, age at first calving, season and year of calving and parity on reproductive performance of Friesian cows under semiarid conditions in Egypt. ArchivaZootechnica. 2010;13(1):60-82
11. Bajwa I R, M S Khan, M A Khan, K Z Gondal. Environmental factor affecting milk yield and lactation length in Sahiwal cattle. Pakistan Veterinary Journal. 2004;24(1):23-27.

12. Iiatsia E D, T K Muasya, W B Muhuyi, A K Kahi. Milk production and reproductive performance of Sahiwal cattle in semi-arid Kenya National Animal Husbandry Research Institute, Naivasha. Kenya. Tropical Science Journal. 2007;42(3):24-27.

13. Maryam A L, R Maryam, R Mahdie. Trends in calving ages and calving interval for Iranian Holsteins Friesian Department Veterinary Medicine Shiraz University Iran. Tropical Animal Health and Production. 2009;41(7):1283-1288.

14. Aslam M, M Nawaz, M S Khan. Comparative performance of some cattle breeds under Barani conditions of Pakistan. International Journal of Agriculture \& Biology. 2002;8 (4):565-567.

15. Hassan F, M S Khan. Performance of crossbred dairy cattle at military dairy farms in Pakistan. The Journal of Animal and Plant Sciences. 2013;23(3):05-714.

16. Khatri P, KB Mirbahar, M U Samo, H K Kunbhar. Productive performance of Red Sindhi cattle. Pakistan Veterinary Journal. 2004;3(6):353-355.

17. Baloch H K. Performance analysis of Red Sindhi cattle under semiintensive management at Hub, Baluchistan M. Sc. Thesis, Livestock Management, Sindh Agriculture University, Tandojam. 2005.

18. Mustafa M I, M Latif, M K Bashir, B Ahmad. Reproductive performance of Red Sindhi cattle under hot and humid environment of Baluchistan province of Pakistan. Pakistan Veterinary Journal. 2003;23(2):66-72.

19. Raza H S, KZ Gondal Arshad Eqbal, A Shafiq. A study on effect of seasons on milk production and calving pattern in Nili-Ravi buffaloes. Buffalo Bulletin . 1999;18(1):16-19.

20. Zia-Ur-Rehman, M S Khan, S A Bhatti, J Iqbal, A Iqbal. Factors affecting first lactation performance of Sahiwal cattle in Pakistan. ArchivaTierz. Dummerstorf. 2008;51(4):305-317.

21. Khosroshahi1 Z T, S A Rafat, D Shoja. Effects of non-genetic factors in milk production and composition in east Azerbaijan native buffaloes of Iran. Buffalo Bulletin. 2011;30(3):220-209.

22. Abdein H A Zain El, S A Makkawi. Age at puberty and the effect of season of birth on age and body weight at first conception in HolsteinFriesian Heifers born in the Sudan. Journal of Animal and Veterinary Advance. 2006;5(5):418-422. 